\title{
PREPARATION, EVALUATION AND STABILITY OF LAMIVUDINE LOADED ALGINATE- TAMARIND MUCILAGE MICROSPHERES
}

\author{
SANTOSH GADA ${ }^{1,2^{*}}$, ANANDKUMAR Y. ${ }^{3}$, C. MALLIKARJUNA SETTY ${ }^{4}$
}

${ }^{1}$ Jawaharlal Nehru Technological University, Kukatpally, Hyderabad, Telangana, India, ${ }^{2}$ KCT College of Pharmacy, Gulbarga, Karnataka. India, ${ }^{3} \mathrm{~V}$ L College of Pharmacy, Raichur, Karnataka, India, ${ }^{4}$ Oxford College of Pharmacy, Bengaluru, Karnataka. India Email: gadasantosh@yahoo.co.in

Received: 29 Apr 2019, Revised and Accepted: 01 Jun 2019

\section{ABSTRACT}

Objective: The objective of the present study was to investigate the possibility of obtaining a controlled, relatively constant effective level of lamivudine microspheres.

Methods: Lamivudine loaded sodium alginate (SA) and tamarind mucilage(TM) mucoadhesive microspheres were prepared by ionic gelation technique with three different proportions of SA and TM with different concentrations of $\mathrm{CaCl}_{2}$. The prepared microspheres were evaluated for drug loading, particle size distribution, surface morphology, FTIR, in vitro wash off, in vitro release and stability studies.

Results: The microspheres were found to be free flowing having diameter ranging from 769.22 to $978.56 \mu \mathrm{m}$, drug encapsulation efficiency (DEE) was found to be 65.28 to $92.33 \%$. Percent drug release after $12 \mathrm{~h}$ were ranging from $85 \pm 1.51$ to $97 \pm 1.44$. In vitro release profile of all formulations shows slow controlled release up to $12 \mathrm{~h}$. In vitro wash off studies shown fairly good mucoadhesivity with $20 \%$ microspheres adhered after $6 \mathrm{~h}$. Stability studies showed that no significant change in particle size and maximum DEE in comparison to the formulation stored at room temperature.

Results: The lamivudine loaded SA-TM mucoadhesive microspheres can be conveniently prepared which showed better result and it may be used full for controlling the drug release and improve the bioavailability.

Keywords: Microspheres, Mucoadhesive, Tamarind, Mucilage, In vitro, Lamivudine

(C) 2019 The Authors. Published by Innovare Academic Sciences Pvt Ltd. This is an open access article under the CC BY license (http://creativecommons.org/licenses/by/4.0/] DOI: http://dx.doi.org/10.22159/ijap.2019v11i4.33808

\section{INTRODUCTION}

Oral drug delivery systems continue to be the most accepted and popular one among all the drug delivery systems as it offers several advantages over the conventional drug delivery systems like improving patient's compliance and convenience due to the reduction of frequency of administration [1]. The formulation of controlled drug delivery systems is important to achieve better clinical efficacy and patient compliance [2], Such systems are highly desirable for drugs that have a short half-life to avoid unnecessary side effects, burst effect or overdose [3, 4]. In addition, controlled release dosage forms ensure optimum and uniform supply of the drug, reduce the frequency of intakes [5, 6], enhance stability [7] and increase absorption of some drugs [8].

Microspheres possess important features among the controlled drug delivery systems by virtue of their small size and efficient carrier characteristics [9], but the success of dosage form is limited due to its residence time. Hence mucoadhesive microsphere drug delivery systems are used to extend the residence time at the site of application, maintain therapeutically effective plasma drug concentration levels for a longer duration, reducing the dosing frequency and minimize fluctuations in the plasma drug concentration at the steady state in the controlled and reproducible manner [10-12].

Recently, the mucoadhesive polymers have drawn great interest in the designing of oral drug delivery systems to prolong the gastric residence time for the dosage forms as well as to facilitate the intimate contact with an underlying absorptive surface to enhance the oral bioavailability of drugs $[13,14]$.

Amongst various natural polymers, alginates have been found extensively used, as the matrix in various drug delivery applications due to its hydrogel-forming properties [15]. Alginates are polysaccharides obtained from marine brown algae (Laminaria hyperborean, Ascophullumnodosum, Macrocystispyriferaetc.) [16], which are the monovalent form of alginic acid belonging to the family of linear copolymers, composed of two monomeric units, $\beta$-Dmannuronic acid (M) and $\alpha$-L-guluronic acid (G). These residues are arranged in homopolymeric blocks (GG and MM) and heteropolymeric blocks (MG) [17]. Alginates undergo ionotropic gelation in aqueous solution in the presence of divalent cations like $\mathrm{Ca}^{2+}, \mathrm{Ba}^{2+}, \mathrm{Pb}^{2+}, \mathrm{Cu}^{2+}, \mathrm{Cd}^{2+}, \mathrm{Zn}^{2+}$, and the like and trivalent cation like $\mathrm{Al}^{3+}$, due to the ionic interaction and intermolecular bonding between the carboxylic acid groups located on the polymer backbone and cations [18]. Though alginates have mucoadhesive property, but, the cross-linked alginate beads are usually fragile [19, 20]. Therefore, to overcome this fragile character, blending of different mucoadhesive polymers is done. Blending with suitable polymers may improve the drug encapsulation efficiency (DEE), which is usually lower in only alginate microspheres prepared by ionotropic gelation method.

One cheap and naturally derived polymer is tamarind mucilage (TM) obtained from the seeds of Tamarindus indica L., a common tree of India and South East Asia. Tamarind is composed of $(1 \rightarrow 4)-\beta$-Dglucan backbone substituted with side chains of $\alpha$-D-xylopyranose and $\beta$-D-galactopyranosyl $(1 \rightarrow 2)$ - $\alpha$-D-xylopyranose linked $(1 \rightarrow 6)$ to glucose residues $[21,22]$. It is used as a binder, gelling, thickening, emulsifying, and suspending agent in different pharmaceutical formulations and acts as a stabilizer in food and pharmaceutical industries $[23,24]$. Tamarind mucilage has been described as a viscosity enhancer showing mucomimetic, and mucoadhesive property [25]. Again, due to its hydrophilic and mucoadhesive property, it finds its use in the development of mucoadhesive drug delivery systems [26].

Lamivudine is an anti-retroviral agent which is chemically designated as 4-amino-1-[(2R, 5S)-2-(hydromethyl)-1,3-oxathiolan5-yl]-1,2-dihydropyrimidin-2-one, used in the treatment of HIV [27]. Lamivudine (3-TC), 2-deoxy-3-thiacytidine, is a potent nucleoside analog reverse transcriptase inhibitor with very low cellular cytotoxicity. Moreover, lamivudine is active against zidovudineresistant human immunodeficiency virus (HIV) $[28,29]$. Lamivudine has approximately $80 \%$ oral bioavailability in human with the usual dosage of $150 \mathrm{mg}$ twice daily in combination with other antiretroviral agents [30]. Conventional oral formulations of lamivudine are administered multiple times a day because of its 
moderate half-life (5-7 h) [31]. Treatment of HIV using conventional formulations of lamivudine is found to have many drawbacks, such as drug accumulation due to frequent dosing, plasma concentration fluctuation, poor patient compliance, and high cost [32].

Incorporation of lamivudine in controlled release or sustained release dosage forms such as mucoadhesive microspheres may control its absorption from the gastrointestinal tract and overcome the variability problems. Therefore, an attempt to prepare, TM blending with SA to produce microspheres, which facilitate an intimate contact with the mucous membranes (i.e., mucoadhesion or bioadhesion), and thus the release of lamivudine at a controlled rate over an extended period to maximize the therapeutic effect is made.

The objectives of the investigation were to isolate TM from the seeds of Tamarindus indica L. seeds, to prepare, evaluate and characterize SA-TM mucoadhesive microspheres by ionotropic gelation technique.

\section{MATERIALS AND METHODS}

\section{Materials}

The pure drug Lamivudine was obtained by Hetero Drugs Pvt ltd, Hyderabad (Telangana, India). Sodium alginate and Calcium chloride were procured from yarrow chemicals and SD fine chemicals Mumbai respectively. Tamarind seeds were procured from the local market. All other reagents used were of analytical grades and double distilled water was used throughout the studies.

\section{Method}

\section{Isolation of tamarind mucilage}

Raw seeds of tamarind seeds (Tamarindusindica L.) were cleaned with distilled water to remove any extra pulp. Two hundred fifty grams of cleaned seeds were broken into small pieces and grounded into fine powder. Powders were taken in a $1000 \mathrm{ml}$ beaker loaded $500 \mathrm{ml}$ water and boiled on water bath at $80-100{ }^{\circ} \mathrm{C}$ with a constant stirring till a viscous solution was obtained and kept aside for $2 \mathrm{~h}$ for the release of mucilage, then filtered. The filtrate was precipitated out with ethanol in crude form. The precipitated material was filtered through a muslin bag into conical flask and marc is squeezed well in order to remove the mucilage completely, in between hot distilled water $(25 \mathrm{ml})$ was added through the sides of muslin bag. The aqueous filtrate is concentrated to $1 / 3 \mathrm{rd}$ of its volume. The obtained precipitate is settled by keeping in a refrigerator for overnight. After complete settling of the precipitate, it was filtered and dried the residue at $37{ }^{\circ} \mathrm{C}$. The obtained dried powder was reduced to a fine powder and passes through $120 \#$ and subjected for identification test to confirm its identity. The prepared TM powder was stored in desiccators for further study [33-35].

\section{Formulation of microspheres}

Lamivudine loaded SA-TM mucoadhesive microspheres were formulated by using the ionic-gelation technique. Polymer SA was dissolved in distilled water to form a homogenous solution. A homogenous solution of TM was prepared by dissolving in distilled water in a separate beaker. Both the polymer solution and mucilage mixed, to this core material, lamivudine was added and mixed thoroughly. The proportion of drug to polymer was maintained 1:1 in all formulations. The resulting mixture was then added as a thin stream using 21 gauze needles into $100 \mathrm{ml} \mathrm{CaCl}_{2}$ solution. The thin stream droplets were retained in the $\mathrm{CaCl}_{2}$ solution for $15 \mathrm{~min}$ to complete the curing reaction and to produce rigid spheres. The microspheres were collected by filtration and washed repeatedly with water. The obtained microspheres were then air-dried and stored for further characterization [36]. Formulation was shown in table 1.

Table 1: Formulation and processing parameters of lamivudine based SA-TM mucoadhesive microspheres

\begin{tabular}{llll}
\hline Formulation code & SA: $\mathbf{T M}$ & $\mathbf{C a C l}_{\mathbf{2}} \mathbf{( \% )}$ & DEE $^{*}$ \\
\hline FT-1 & $1: 1$ & 5 & $65.28 \pm 3.81$ \\
FT-2 & $1: 1$ & 7.5 & $73.85 \pm 2.66$ \\
FT-3 & $2: 1$ & 10 & $79.96 \pm 4.06$ \\
FT-4 & $2: 1$ & 5 & $70.65 \pm 3.95$ \\
FT-5 & $2: 1$ & 7.5 & $78.35 \pm 3.26$ \\
FT-6 & $2: 1$ & 10 & $86.35 \pm 3.98$ \\
FT-7 & $3: 1$ & 5 & $77.86 \pm 4.17$ \\
FT-8 & $3: 1$ & 7.5 & $85.89 \pm 3.68$ \\
FT-9 & $3: 1$ & 10 & $92.33 \pm 4.42$ \\
\hline
\end{tabular}

${ }^{*}$ Avg of three determinations, SA-Sodium Alginate; TM-Tamarind Mucilage; DEE-Drug Encapsulation efficiency; PS-Particle Size

\section{Evaluation}

\section{Yield of microspheres}

All the batches of dried microspheres were accurately weighed separately and percentage yield is calculated by using the given equation.

$$
\text { Percentage yeild }=\frac{\text { Practical weight }}{\text { Theoretical weight(polymer+drug) }} \times 100
$$

\section{Determination of DEE (\%)}

Accurately weighed, $100 \mathrm{mg}$ of microspheres were taken and crushed using pestle and mortar. The crushed powders of drugloaded microspheres were placed in $500 \mathrm{ml}$ of phosphate buffer $\mathrm{pH}$ 7.4 and kept for $24 \mathrm{~h}$ with occasional shaking at $37 \pm 0.5^{\circ} \mathrm{C}$.

After the stipulated time, polymer debris formed after the disintegration of microspheres was removed by filtration. The drug content in the filtrate was determined using a UV-VIS spectrophotometer (Shimadzu, Japan) at $271 \mathrm{~nm}$ [37]. The DEE of microspheres was calculated using the following formula:

$$
\text { Encapsulation effeciency }=\frac{\text { Actual amount of drug encapsulated }}{\text { Theoretical drug content }} \times 100
$$

\section{Drug-excipients interaction studies}

Assessment of possible incompatibilities between a pure drug substance, polymer and mucilage forms an important part of the development of dosage form. Samples were reduced to powder and analysed with $\mathrm{KBr}$ pellets by using a Fourier transform infrared (FTIR) spectroscope (Perkin Elmer Spectrum). The pellet was placed in the sample holder and spectral scanning was taken in the wavelength region ranging between 4000 and 4001 cat a resolution of $4 \mathrm{~cm}^{-1}$ with a scan speed of $1 \mathrm{~cm} / \mathrm{sec}$ [38].

\section{Particle size (sieving methods) determination}

This test was performed with the help of sieves of different size. They were arranged in sieve shaker in such a way that the coarsest sieve on top and the finer sieves at the bottom. Microspheres were placed on the top and run the machine to segregate, the weight of the microspheres remain on the sieves were collected and weighed [39]. The sizes of the microspheres were determined by carrying out studies in triplicate and its average size is calculated by using the given following equation.

$$
\mathrm{D}_{\text {Avg }}=\frac{\sum \text { Xifi }}{\text { fi }}
$$

Where, $\mathrm{X}_{\mathrm{i}}$-Mean size range; 
$\mathrm{f}_{\mathrm{i}}$-Percentage microspheres retained on the smaller sieve range.

\section{Surface morphology studies}

The external morphology of the microspheres was studied using scanning electron microscopy (SEM). Mucoadhesive microspheres of lamivudine loaded SA-TM were fixed on aluminium studs and coated with gold using a sputter coater SC 502, under vacuum [0.1 $\mathrm{mm} \mathrm{Hg}$ ] and are analyzed using-Model JSM-840 A, Joel. Japan. The samples were then randomly scanned, and photomicrographs were taken [40].

\section{In vitro wash off test for mucoadhesion}

The mucoadhesivity of lamivudine loaded SA-TM mucoadhesive microspheres were evaluated by in vitro wash-off method. Freshly excised pieces of goat intestinal mucosa $(2 \times 2 \mathrm{~cm})$ (collected from the slaughterhouse) were mounted on a glass slide $(7.5 \times 2.5 \mathrm{~cm})$ using cyanoacrylate glue. About 50 microspheres were spread onto the wet tissue specimen, and the prepared slide was hung onto a groove of the disintegration test apparatus. The tissue specimen was given a regular up and down movement at $37 \pm 0.5^{\circ} \mathrm{C}$ loaded $900 \mathrm{ml}$ of phosphate buffer ( $\mathrm{pH}$ 7.4). After regular time intervals, the machine was stopped and the number of microspheres still adhering to the tissue was counted [41].

\section{Stability studies}

All the formulations were studied for stability profile at $40{ }^{\circ} \mathrm{C} \pm 2$ ${ }^{\circ} \mathrm{C} / 75 \% \pm 5 \%$ RH for 6 mo (Climatic zone IV condition for accelerated testing) to assess their stability. The protocol of stability studies was in compliance with the WHO recommended ICH guidelines for stability testing intended for the global market. After intervals of 30 , $60,90,120$ and $180 \mathrm{~d}$, samples were withdrawn and retested for DEE (Drug Content) and Particle size [42].

\section{In vitro drug release studies}

To study the in vitro dissolution profile, microspheres equivalent to $50 \mathrm{mg}$ of lamivudine were filled in hard gelatin capsules. Dissolution studies were performed using the dissolution test apparatus USP-II with paddle (Electrolab, Mumbai, India). The phosphate buffer $\mathrm{pH}$ $7.4(900 \mathrm{ml})$ was used as dissolution medium at $37 \pm 1{ }^{\circ} \mathrm{C}$. The paddle was rotated at $50 \mathrm{rpm}$. The $5 \mathrm{ml}$ of samples were withdrawn on definite time intervals using pipette and immediately replaced with an equal quantity of phosphate buffer $\mathrm{pH}$ 7.4. The amount of drug released was determined using (collected aliquots were filtered and suitably diluted) UV-VIS spectrophotometer (Shimadzu, Japan) at $271 \mathrm{~nm}$ against a blank (phosphate buffer, $\mathrm{pH}$ 7.4). In order to predict and correlate the in vitro release behaviour of lamivudine from SA-TM mucoadhesive microspheres and marketed tablet Lamivir, data were fitted into a suitable mathematical model. The studies were carried out in triplicate. The in vitro dissolution data were tabulated and computed by using dissolution software viz., PCP DISSO V3.0.

\section{RESULTS AND DISCUSSION}

Isolation of tamarind mucilage and preparation of lamivudine loaded SA-TM mucoadhesive microspheres

Mucilage was isolated from tamarind seeds (Tamarindusindica L.) and the average yield of mucilage was found to be $16.32 \% \mathrm{w} / \mathrm{w}$. The lamivudine loaded different ratio of isolated TM and SA blend (1:1, $1: 2$ and 1:3) with different concentrations of $\mathrm{CaCl}_{2}(5-10 \%)$ as crosslinking material by ionotropic gelation method were prepared, as formulation shown in table 1. Rigid and discrete lamivudine loaded SA-TM mucoadhesive microspheres were obtained when dispersion mixture of SA, TM and core material lamivudine added in a solution containing calcium ions.

\section{Encapsulation efficiency}

The DEE in lamivudine loaded SA-TM mucoadhesive microspheres were within the range between $65.28 \pm 3.14$ and $92.33 \pm 3.93 \% \mathrm{w} / \mathrm{w}$ (table 1). The higher DEE in lamivudine loaded SA-TM mucoadhesive microspheres was seen in formulation FT9, where TM to SA blend ratio as $1: 3$ and the concentration of cross-linking material, $\mathrm{CaCl}_{2}$ was $10 \% \mathrm{w} / \mathrm{v}$. The DEE was increased with decreasing TM to SA blend ratios and increasing cross-linking concentrations. This may be due to the high degree of cross-linking as the amount of SA in the polymer blend, and concentration of crosslinking material (i.e. $\mathrm{CaCl}_{2}$ ) solution was increased [43].

When drug-loaded polymer blend (SA-TM) was added into a solution of $\mathrm{CaCl}_{2}$, the calcium ions replaces the sodium ions of $\mathrm{SA}$ to form calcium alginate, which provides cross-linking to form the cross-linked microspheres. Again, at a lower concentration of $\mathrm{CaCl}_{2}$, the microspheres might have larger pores due to insufficient crosslinking that resulted in lower drug encapsulation [44].

\section{Particle size and surface morphological characteristics}

The particle size of lamivudine loaded SA-TM microspheres for each formulation was carried out by sieve analysis method. The diameters of these microspheres were within the size range of $769.22 \pm 7.42$ to $978.49 \pm 18.72 \mu \mathrm{m}$ (table 1 ). Increases in the diameter of these microspheres were found with the increasing proportion of TM into formulations. This is may be due to the increase in viscosity of polymer blend solution with the incorporation of TM in an increasing ratio that in turn increased the size of the droplet. Again, the reduction in the size of the particle of these formulated SA-TM mucoadhesive microspheres was observed when there is an increase in the concentration of $\mathrm{CaCl}_{2}$ in solution. This may due to shrinkage of the polymeric gel by a higher degree of cross-linking with the high concentration of crosslinker (i.e. $\mathrm{CaCl}_{2}$ ) [45]. It was also observed that the DEE of lamivudine loaded SA-TM mucoadhesive microspheres were appeared to decrease with increasing diameter. The morphological analysis of microspheres was done by SEM and presented in fig. 1. The SEM photograph indicated that microspheres were spherical particles of rough surfaces with no tendency to aggregate. Their surface morphologies appeared to have a rough surface with characteristic pores, large wrinkles, and cracks. These pores, cracks, and wrinkles may be due to polymeric gel collapsing during the drying process of microspheres.

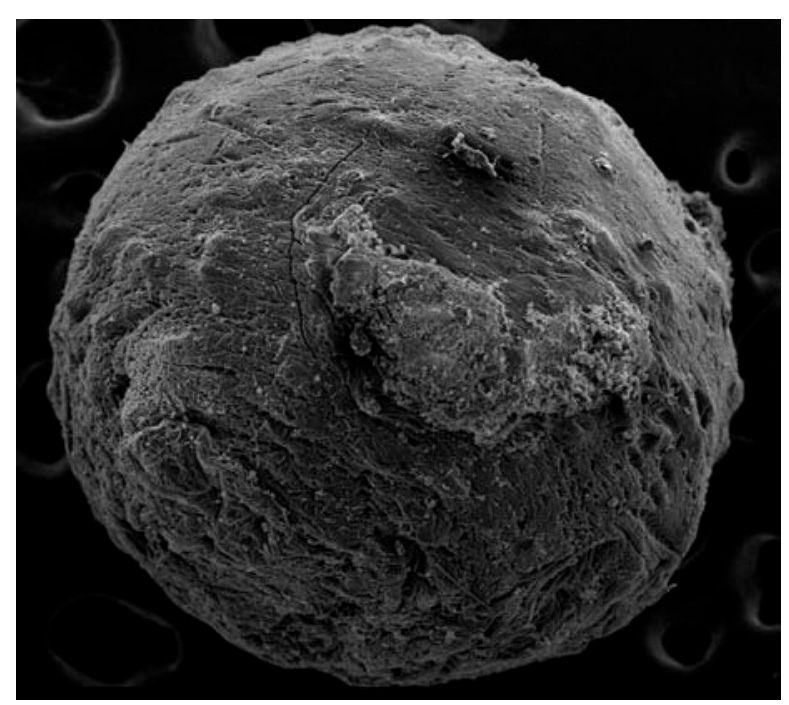

Fig. 1: SEM photograph of lamivudine loaded SA-TM mucoadhesive microsphere

\section{FTIR spectroscopic analysis}

FTIR spectrometric analysis was performed to confirm the compatibility of lamivudine with polymers used to prepare microspheres formulation. The FTIR spectra of lamivudine, SA, TM, and lamivudine loaded SA-TM mucoadhesive microspheres were shown in fig. 2. In the FTIR spectra of lamivudine loaded SA-TM mucoadhesive microspheres, various characteristic peaks of sodium alginate, tamarind, and lamivudine were appeared without any significant shifting of peaks. Suggesting, there were no interactions between the lamivudine and the polymers (TM, and SA) used. 


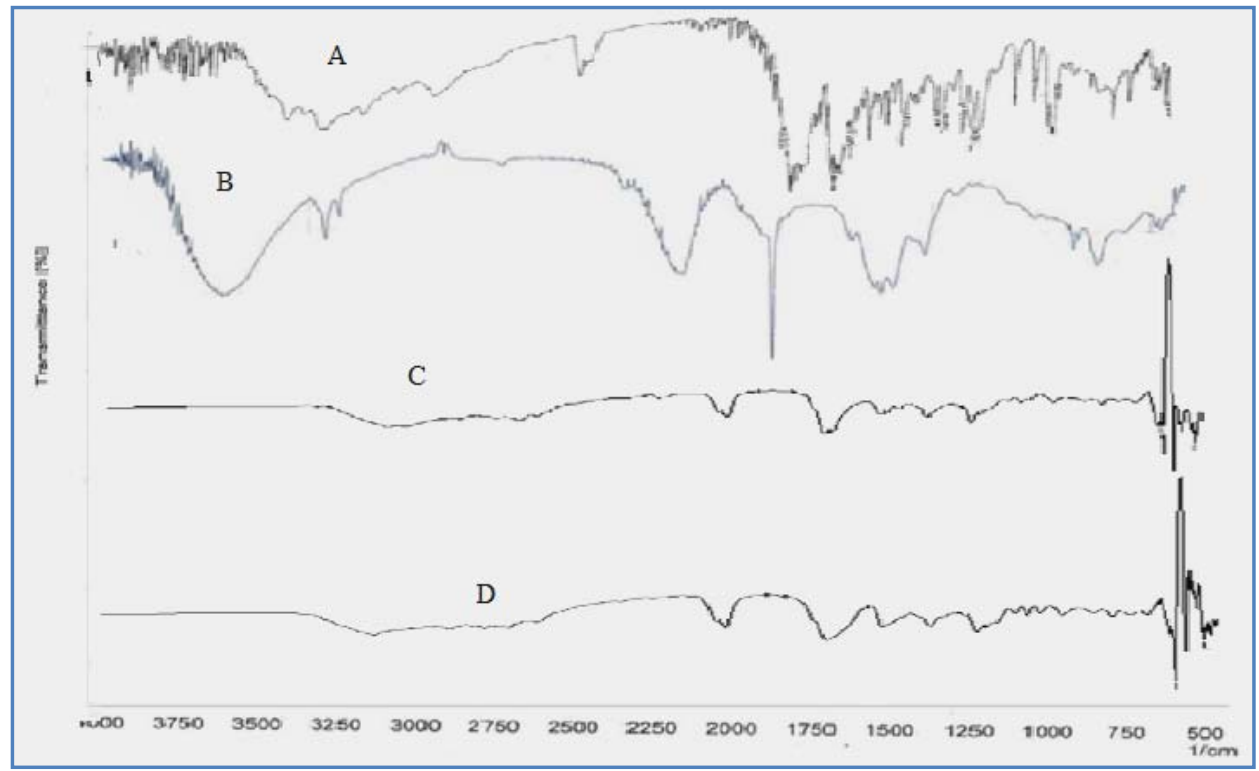

Fig. 2: FTIR spectra of A) Pure drug lamivudine, B) SA, C) TM and D) Lamivudine loaded SA-TM mucoadhesive microspheres

\section{In vitro drug release}

Lamivudine release from various SA-TM microspheres was studied in simulated intestinal $\mathrm{pH}$ (phosphate buffer, $\mathrm{pH}$ 7.4). Various lamivudine loaded SA-TM microspheres showed the controlled release of lamivudine over $12 \mathrm{~h}$. The lamivudine release from SA-TM microspheres was slow and dependent on both the proportion of the polymer (TM, and SA) and the percentage of cross-linking agent $\mathrm{CaCl}_{2}$. The release of lamivudine from SA-TM mucoadhesive microspheres was observed85.16 \pm 1.51 to $97.37 \pm 2.44$ inphosphate buffer, pH 7.4 after $12 \mathrm{~h}$ (fig. 3). It can be observed that comparatively higher proportion of TM in formulations, the more hydrophilic property of the TM combined better with water to form a viscous gel structure, which might blockade the pores on the surface of microspheres and controlled the release profile of the drug, lamivudine. Also, the release of lamivudine from SA-TM microspheres formulated with a higher concentration of $\mathrm{CaCl}_{2}$ comparatively controlled than the microspheres prepared with a lower concentration of $\mathrm{CaCl}_{2}$ [46].

\section{Mucoadhesive (in vitro wash-off test)}

The in vitro wash-off test to know mucoadhesivity of these SA-TM microspheres loaded lamivudine was carried out at simulated intestinal pH (phosphate buffer, $\mathrm{pH}$ 7.4) for $6 \mathrm{~h}$. The percentage of microspheres adhering to the goat intestinal mucosal tissue varied from $15.55 \pm 0.58$ to $19.60 \pm 3.25 \%$ in phosphate buffer after $6 \mathrm{~h}$ (fig. 4). The results of the wash-off test indicated that the lamivudine loaded SA-TM microspheres had fairly good mucoadhesive properties.

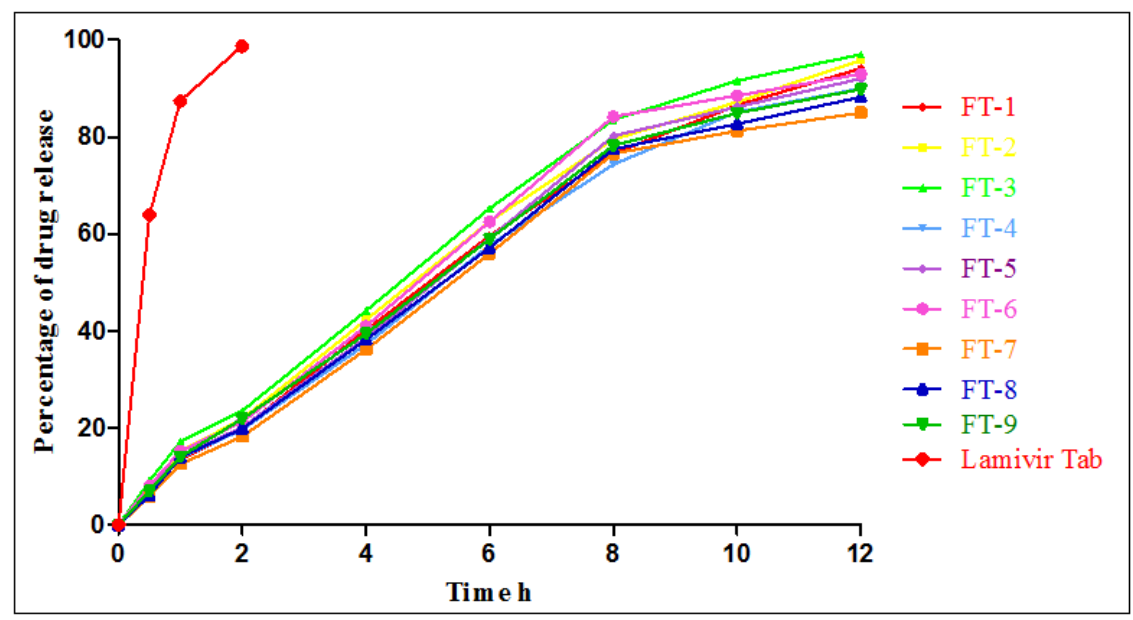

Fig. 3: In vitro dissolution profile of lamivudine loaded SA-TM mucoadhesive microspheres and lamivir tab

\section{Stability studies}

The stability study of the microspheres was carried out at accelerated temperatures. The percentage of drug content was estimated as a part of storage stability studies considering initial drug content as $100 \%$. The thermal degradation of optimized formulation were studied by keeping the formulations at accelerated temperatures of $40{ }^{\circ} \mathrm{C} \square \pm 2 \quad{ }^{\circ} \mathrm{C} / 75 \% \mathrm{RH} \square \pm 5 \% \mathrm{RH}$. The physical observations of samples, particle size, DEE given in table 2 and 3 . The product retained its spherical geometry and did not show shrivelling tendency during the 6-month storage period. The results of the stability studies indicated that the lamivudine contaminating SA-TM microspheres were stable at all conditions but most stable at room temperature. 


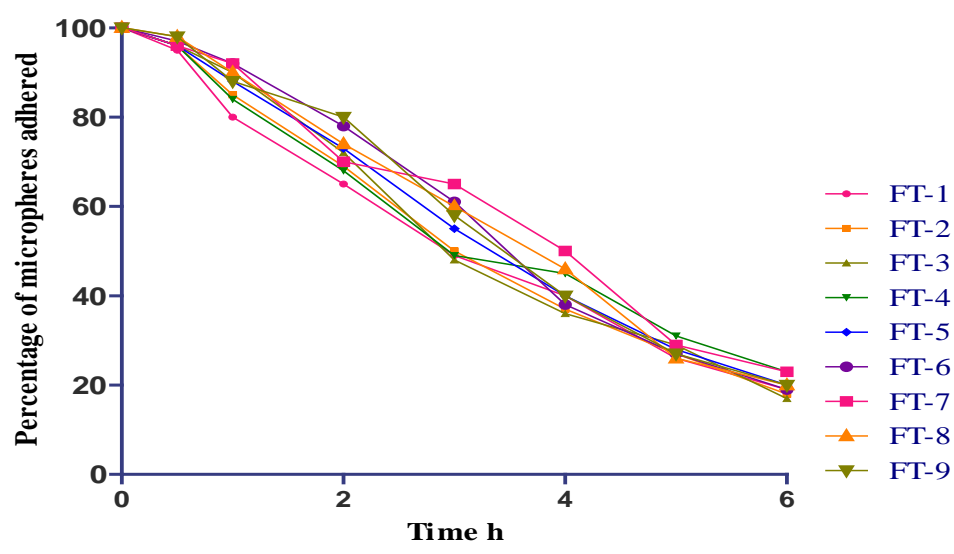

Fig. 4: In vitro wash off test to know mucoadhesiveness of lamivudine loaded SA-TM microspheres

Table 2: Stability study of particle size for optimized batches of lamivudine loaded SA-TM mucoadhesive microspheres

\begin{tabular}{|c|c|c|c|c|}
\hline \multirow[t]{2}{*}{ Formulation code } & \multirow{5}{*}{$\frac{\text { Parameter }}{\text { Particle Size }}$} & \multicolumn{3}{|c|}{ Observation during accelerated stability studies* } \\
\hline & & Initial & 3 Mo & $6 \mathrm{Mo}$ \\
\hline FT-3 & & $873.13 \pm 16.26$ & $878.05 \pm 15.91$ & $879.23 \pm 13.85$ \\
\hline FT-6 & & $823.47 \pm 13.28$ & $831.24 \pm 12.67$ & $831.68 \pm 14.25$ \\
\hline FT-9 & & $769.22 \pm 10.19$ & $776.35 \pm 16.38$ & $780.35 \pm 11.98$ \\
\hline
\end{tabular}

*Avg of three determinations

Table 3: Stability study of DEE for optimized batches of lamivudine-containing SA-TM mucoadhesive microspheres

\begin{tabular}{llll}
\hline Formulation code & Parameter & \multicolumn{3}{l}{ Observation during accelerated stability studies* } \\
\cline { 3 - 4 } & DEE & Initial & 3 Mo \\
\cline { 3 - 4 } FT-3 & & $79.96 \pm 4.06$ & $79.02 \pm 3.86$ \\
FT-6 & & $86.35 \pm 3.98$ & $85.92 \pm 2.94$ \\
FT-9 & & $92.33 \pm 4.42$ & $91.12 \pm 4.08$ \\
\hline
\end{tabular}

*Avg of three determinations

\section{CONCLUSION}

The lamivudine loaded SA-TM mucoadhesive microspheres by ionotropic gelation technique was developed and evaluated. The DEE of these microspheres were within the range. The prepared microspheres were of spherical shape with rough surfaces, and their average particle size varied with coat ratio and calcium chloride concentration FTIR analysis suggested that there were no interactions between the lamivudine and the polymers (TM, and SA) used. All these SA-TM mucoadhesive microspheres exhibited fairly good mucoadhesivity. The method of preparation for SA-TM mucoadhesive microspheres for oral lamivudine delivery was found to be very simple and reproducible. Finally, it can be said that this lamivudine loaded SA-TM mucoadhesive microspheres are very much suitable for controlled systemic administration of lamivudine through controlled drug release, increase bioavailability their by improving patient compliance.

\section{ACKNOWLEDGMENT}

The authors are grateful to principal and management of V. L. College of Pharmacy, Raichur and KCT College of Pharmacy Gulbarga for the smooth conduct of research experiments.

\section{AUTHORS CONTRIBUTIONS}

All the author have contributed equally

\section{CONFLICT OF INTERESTS}

The authors report no conflicts of interest

\section{REFERENCES}

1. Velmurugana S, Ali MA. Preparation and evaluation of maraviroc mucoadhesive microspheres for gastro retentive drug delivery. Int J Pharm Pharm Sci 2015;7:208-14.
2. Abdul M, Rao AS, Martha S, Sirisha Y, Chandrika PU. Development of a floating multiple unit controlled-release beads of zidovudine for the treatment of AIDS. JOPR J Pharm Res 2012;6:78-83.

3. Biswal I, Dinda A, Das D, Si S, Chowdary KA. Encapsulation protocol for highly hydrophilic drug using non-biodegradable polymer. Int J Pharm Pharm Sci 2011;3:256-9.

4. Ma N, Xu L, Wang Q, Zhang X, Zhang W, Li Y, et al. Development and evaluation of new sustained-release floating microspheres. Int J Pharm 2008;358:82-90.

5. Basak SC, Kumar KS, Ramalingam M. Design and release characteristics of sustained release tablet containing metformin HCl. Br J Pharm Sci 2008;44:477-83.

6. Patel PN, Patel MM, Rathod DM, Patel JN, Modasiya MMK. Sustain release drug delivery: a theoretical prospective. J Pharm Res 2012;5:4165-8.

7. Raffin RP, Colome LM, Schapoval EES, Pohlmann AR, Guterres SS. Increasing sodium pantoprazole photostability by microencapsulation: Effect of the polymer and the preparation technique. Eur J Pharm Biopharm 2008;69:1014-8.

8. Zyazici M, Sevgi F, Ertan G. Micromeritic studies on nicardipine hydrochloride microcapsules. Int J Pharm 1996;138:25-35.

9. Dasari A, Velmurugana S. Formulation and evaluation of nevirapine mucoadhesive microspheres. Int J Pharm Pharm Sci 2015;7:342-8.

10. Deshmukh MT, Mohite SK. Preparation and evaluation of mucoadhesive microsphere of fluoxetine Hcl. Int J Pharm Sci Res 2017;8:3776-85.

11. Vasir JK, Tambwekar K, Garg S. Bioadhesive microspheres as a controlled drug delivery system. Int J Pharm 2003;255:13-32.

12. Chowdary KPR, Srinivas Rao S. Mucoadhesive microspheres and microcapsules: current status. Indian J Pharm Sci 2005;67:141-50. 
13. Chowdary KR, Rao YS. Mucoadhesive microspheres for controlled drug delivery. Biol Pharm Bull 2004;27:1717-24.

14. Jain SK, Chourasia MK, Jain AK, Jain RK, Shrivastava AK. Development and characterization of mucoadhesive microspheres bearing salbutamol for nasal delivery. Drug Delivery 2004;11:113-22.

15. Yadav SK, Khan G, Bonde GV, Bansal M, Mishra B. Design, optimization and characterizations of chitosan fortified calcium alginate microspheres for the controlled delivery of dual drugs. Artif Cells Nanomed Biotechnol 2018;46:1180-93.

16. George M, Abraham TE. Polyionic hydrocolloids for the intestinal delivery of protein drugs: alginate and chitosan-a review. J Controlled Release 2006;114:1-14.

17. Smidsrod 0, Draget KI. Chemistry and physical properties of alginates. Carbohydr Eur 1996;14:6-13.

18. El-menshawe SE, Kharshoum RM, Hamad DS, Halawa A. Effect of biodegradable copolymers and divalent cations on the sustained release ability of propranolol hydrochloride loaded biomaterial microspheres. Int J Pharm Pharm Sci 2016;8:311-7.

19. Kroll E, Winnik FM, Ziolo RF. In situ preparation of nanocrystalline $\gamma-\mathrm{Fe}_{2} \mathrm{O}_{3}$ in iron (II) cross-linked alginate gels. Chem Mater 1996;8:1594-6.

20. Llanes F, Ryan DH, Marchessault RH. Magnetic Nanostructured composites using alginates of different $\mathrm{M} / \mathrm{G}$ ratios as the polymeric matrix. Int J Biol Macromol 2000;27:35-40.

21. Gowda DV, Nawaz M, Vishnu DM. Design and evaluation of carboxymethyl tamarind kernel polysaccharide (cmtkp) controlled release spheroids/pellets and investigating the influence of compression. Int J Pharm Pharm Sci 2014;6:103-9.

22. Jana S, Lakshman D, Sen KK, Basu SK. Development and evaluation of epichlorohydrin cross-linked mucoadhesive patches of tamarind seed polysaccharide for buccal application. Int J Pharm Sci Drug Res 2010;2:193-8.

23. Jani GK, Shah DP, Prajapati VD, Jain VC. Gums and mucilages: versatile excipients for pharmaceutical formulations. Asian J Pharm Sci 2009;4:309-23.

24. Sahoo R, Sahoo S, Nayak PL. Release behavior of anticancer drug paclitaxel from tamarind seed polysaccharide galactoxyloglucan. Eur J Sci Res 2010;47:197-206.

25. Kulkarni D, Dwivedi AK, Sarin JPS, Singh S. Tamarind seed polyose: a potential polysaccharide for sustained release of verapamil hydrochloride as a model drug. Indian J Pharm Sci 1997;59:1-7.

26. Patel B, Patel P, Bhosale A, Hardikar S, Mutha S, Chaulang G. Evaluation of tamarind seed polysaccharide (TSP) as a mucoadhesive and sustained release component of nifedipinebuccoadhesive tablet and comparison with HPMC and Na CMC. Int J Pharm Tech Res 2009;1:404-10.

27. Anumolu PD, Anusha K, Mrudula Kiran A, Monika P, Sowndarya NSKR, Sunitha G. Liquid chromatographic quantification of ternary mixture of anti-viral drugs and application to assessment of their tablet dosage form. Int J Pharm Pharm Sci 2016;8:237-40

28. Benjamin J Eckhardt, Roy M Gulick. Drugs for HIV infection. Infectious Diseases 2017;4:1293-308.

29. Charles F. Antiretroviral agents and treatment of HIV infection. Goodman and Gilman's, The Pharmacological Basis of Therapeutics. 12th ed. New York: McGraw-Hill; 2011. p. 1634-5.
30. Piliero PJ. Pharmacokinetic properties of nucleoside/ nucleotide reverse transcriptase inhibitors. J Acquir Immune Defic Syndr 2004;37:S2-S12.

31. Betty JD, Jennifer C. Human immunodeficiency virus infectionantiretroviral therapy. In: Richard AH, David JQ. editors. The textbook of therapeutics: drug and disease management. 8th ed. Philadelphia: Lippincott Williams and Wilkins; 2006. p. 2137-58.

32. Moyle G. Clinical manifestations and management of antiretroviral nucleoside analog-related mitochondrial toxicity. Clin Ther 2000;22:911-36.

33. Deveswaran R, Bharath S, Furtado S, Abraham S, Basavaraj BV, Madhavan V. Isolation and evaluation of tamarind seed polysaccharide as a natural suspending agent. Int J Pharm Biol Arch 2010;1:360-3.

34. Erik AR, Angelica RG, Raquel GR, Victor VG, Cesar PA. Rheological properties of tamarind (Tamarindusindica L.) seed mucilage obtained by spray-drying as a novel source of hydrocolloid. Int J Biol Macromol 2018;107:817-24.

35. Panda BB, Mohapatra S, Mallik S, Acharya P. Effect of tamarind seed mucilage on rheological properties: evaluation of suspending properties. Int Res J Pharm Sci 2010;1:8.

36. Gada SG, Anandkumar Y, Setty CM. Preparation and evaluation of zidovudine mucoadhesive microspheres. Eur J Pharm Med Res 2017;4:570-6.

37. Tavakol M, Ebrahim VF, Sameereh HN. The effect of polymer and $\mathrm{CaCl}_{2}$ concentrations on the sulfasalazine release from alginate-N, O-carboxymethyl chitosan beads. Prog Biomater 2013;2:10.

38. Obeidat WM, Price JC. Preparation and evaluation of Eudragit S 100 microspheres as $\mathrm{pH}$-sensitive release preparations for piroxicam and theophylline using the emulsion-solvent evaporation method. J Microencapsul 2006;23:195-202.

39. Sharma M, Jain K, Dev SK, Choudhury PK. Formulation and evaluation of sodium alginate beads by emulsion gelation method. Asian J Pharm 2017;11:S101-6.

40. Maiti S, Dey P, Banik A, Biswanath S, Ray S, Kaity S. Tailoring of locust bean gum and development of hydrogel beads for controlled oral delivery of glipizide. Drug Delivery 2010;17:288-300.

41. Verma S, Kumar V, Jyoti, Mishra DN. Formulation, evaluation and optimization of mucoadhesive microspheres of acyclovir. Bull Pharm Res 2014;4:14-20.

42. Nagasree K, Chowdary GV, Kumar MCB, Reddy MTR, Bhikshapathi DVRN. Design and evaluation of sodium alginate microspheres loaded with gatifloxacin. Der Pharm Lett 2016;8:361-70.

43. Pal DK, Nayak AK. Novel tamarind seed polysaccharide-alginate mucoadhesive microspheres for oral gliclazide delivery: in vitro-in vivo evaluation. Drug Delivery 2012;19:123-31.

44. Sharma VK, Bhattacharya A. Release of metformin hydrochloride from Ispaghula-sodium alginate beads adhered on cock intestinal mucosa. Indian J Pharm Educ Res 2008;42:365-72.

45. Nayaka AK, Saquib MHS, Beg S, Alam MI. Mucoadhesive beads of gliclazide: design, development, and evaluation. Sci Asia 2010;36:319-25.

46. Princely S, Saleem BN, Nandhakumar S, Dhanaraju MD. Controlled delivery of antiretroviral drug-loaded cross-linked microspheres by ionic gelation method. Asian J Pharm Clin Res 2016;9:264-71. 